\section{LA BIOÉTICA DESDE LA FILOSOFÍA DE ZUBIRI}

\author{
Carlos Alberto Pose Varela \\ Universidad de Santiago de Compostela \\ carlospose@zubiri.net
}

\section{BIOETHICS FROM THE PHILOSOPHY OF ZUBIRI}

Cómo citar este artículo/Citation: Pose Varela, C. A. (2016). La bioética desde la filosofía de Zubiri. Arbor, 192 (780): a335. doi: http://dx.doi.org/10.3989/arbor.2016.780n4011
Copyright: (C) 2016 CSIC. Este es un artículo de acceso abierto distribuido bajo los términos de la licencia Creative Commons Attribution (CC BY) España 3.0.
RESUMEN: La historia de la ética muestra que la ética es un saber que se ha ido elaborando progresivamente. Su construcción ha dependido de muchos factores. A partir de Kant la ética se hace universal y categorial, pero hasta entonces nunca lo fue. Anteriormente, al menos con Sócrates y Aristóteles, la ética se basaba en la deliberación como método de investigación de lo bueno; y lo bueno se decía de muchas maneras. En este artículo presentamos una explicación de esta variedad de éticas desde la filosofía de Zubiri. El enfoque que Zubiri da de la vida moral en los años 50, es preciso revisarlo en los años 80 desde la inteligencia sentiente. En los años 50 Zubiri hablaba de la idea de ser humano como factor fundamental en la construcción de la ética. Pero existe otro factor determinante: la intelección y la valoración como modo de construcción de la ética o bioética.

PALABRAS CLAVE: bioética; constructivismo; ética; idealismo; intelección; positivismo; Zubiri.
ABSTRACT: The history of ethics reveals it to be a knowledge that has developed progressively with a construction dependent on numerous factors. From Kant onwards, ethics became universal and categorical, and had never been so until that time. Previously, at least for Socrates and Aristotle, ethics was based on deliberation as a method of research of that which is good; the good being expressed in multiple ways. In this article, we present an explanation of this kind of ethics from Zubiri's philosophy. Zubiri's approach to moral life in the 50 s must be revised in the $80 \mathrm{~s}$ from the perspective of sentient intelligence. In the 50s, Zubiri spoke of the idea of the human being as a fundamental factor in the construction of ethics. However, there is another factor to be taken into account: intellection and evaluation as a way of constructing ethics or bioethics.

KEYWORDS: bioethics; constructivism; ethics; idealism; intellection; positivism; Zubiri. 


\section{INTRODUCCIÓN}

Este artículo está enfocado al problema de la construcción de la bioética desde la filosofía de Zubiri, teniendo en cuanta una constatación histórica: la pluralidad de éticas que Ilegan a nuestros días. La historia de la ética muestra que la ética es un saber que se ha de ir elaborando sobre la marcha. Su construcción ha dependido de muchas circunstancias, de muchos factores. A partir de Kant la ética se hace universal y categorial, pero hasta entonces nunca lo fue. Anteriormente, al menos en una corriente que tiene su raíz en Aristóteles, la ética, al basarse en la deliberación como método de investigación del bien, se sobreentendía que bien se decía de muchas maneras, o lo que es lo mismo, que las circunstancias, las consecuencias, etc. determinaban el bien.

El enfoque del hecho moral dado por Zubiri en los años 50, es preciso revisarlo hoy a la luz de la trilogía de los años 80. En los años 50 Zubiri hablaba de la "idea de hombre" como factor fundamental en la construcción de la ética. Es uno de los factores. Pero existe otro factor más radical no explicitado allí: la "intelección" como medio de construcción de la ética o bioética. La intelección se despliega en logos y razón, y ambos momentos, para realizar su tarea, tienen que apelar a un "desde" referencial. Dicho de otro modo, los juicios del logos y de la razón siempre son juicios realizados "desde" algo. En ética este "desde" puede ser la "naturaleza" humana (y de ahí la idea de virtud), la "conciencia" moral (y de ahí la idea de deber), la "libertad" de la voluntad (y de ahí la idea de responsabilidad en las consecuencias), la "igualdad" social (y de ahí la idea de justicia). Son cuatro ejemplos, cuatro modos distintos de construir la ética. La pregunta entonces no se hace esperar: ¿Cuál es el "desde" de la bioética actual?

\section{EL CONCEPTO DE POSIBILIDAD COMO CENTRO DEL HECHO MORAL EN ZUBIRI}

La bioética es una disciplina reciente, que todavía se está construyendo. Lo que se construye, o reconstruye, en realidad, son distintas teorías éticas aplicadas a la bioética. Pero esta construcción, curiosamente, está pasando por las mismas etapas que ya han pasado otras disciplinas, y está teniendo, también, más o menos, las mismas dificultades. Esto se pone de manifiesto al observar que la bioética está siendo acosada por las mismas tendencias que ya han acosado a la ética: por un lado, por el idealismo filosófico y religioso, y por otro, por el positivismo jurídico y científico. Esto se traduce en que casi todas las teorías hoy vi- gentes en bioética se han construido de dos modos: de modo "idealista" o de modo "positivista". Por eso, siguiendo la buena consigna de evitar los extremos, puesto que siempre se dejan algo fuera, me propongo describir cómo habría de construirse la bioética según eso que podríamos llamar "realismo moral" al modo de la filosofía zubiriana.

Yendo muy atrás, al curso oral de 1953/4 titulado "El problema del hombre", el término en torno al cual gira el análisis del hecho moral en Zubiri es el de "posibilidad". El bien/mal es una posibilidad, el deber es una posibilidad, la felicidad es una posibilidad, etc. De ahí que Zubiri defina lo moral como "apropiación de posibilidades". "La realidad sustantiva cuyo carácter 'físico' es tener necesariamente propiedades por apropiación, es justo lo que yo entiendo por realidad moral. Lo moral en el sentido usual de bienes, valores y deberes, sólo es posible en una realidad que es constitutivamente moral en el sentido expuesto." (Zubiri, 1986, pp. 343-440). Este sentido tiene que ver con el tipo de propiedades que definen al ser humano, o por el modo de serle propias. Unas le son propias por "emergencia", mientras que otras lo son por "apropiación" o libre decisión. Las primeras son propiedades "naturales", mientras que las segundas son propiedades "creadas", es decir, "posibilidades". He aquí cómo lo explica Zubiri. "En efecto, además de las propiedades formales que emergen 'naturalmente' de las sustancias que la componen, la sustantividad humana tiene otras cuya raíz no es una 'emergencia' sino una 'apropiación': la apropiación de posibilidades. En tal caso, el momento subjetual de la realidad humana cobra un carácter singular. Por un lado, esa realidad es, como cualquier sustancia, sujeto de las propiedades que posee por razón de las sustancias que la componen. Pero por otro, no está 'por-bajo-de' sus propiedades, sino justamente al revés, está 'porencima-de' ellas, puesto que se las apropia por aceptación. En su virtud, yo diría que en este aspecto no es hypokeímenon, sino más bien hyperkeímenon, algo no sólo substante, sino también suprastante. Es decir, es sujeto, pero no en el sentido de que esas propiedades broten de su naturaleza y le sean inherentes como 'sujeto-de' ellas. La virtud o la ciencia, por ejemplo, no son unas notas que el hombre tiene por su naturaleza, al igual que el talento o la estatura, o el color natural de los ojos. En el hombre, antes de su decisión libre hay talento, pero no hay virtud ni ciencia; es 'sujetode' talento y de color, pero no es 'sujeto-de' virtud o ciencia. Virtud y ciencia son sólo dos posibilidades de vida y de realidad humana a diferencia de otras, del vicio y de la practiconería, por ejemplo. Para 'tener- 
las', el hombre tiene que elegir entre esas posibilidades y apropiárselas. Por tanto, respecto de ellas no está en condición de 'sujeto-de' ellas, sino de sujeto determinante de ellas; es suprastante. En cuanto suprastante, la sustantividad humana es tal que por su intrínseca constitución se halla excediendo del área de sus sustancias y no de una manera cualquiera, sino de un modo sumamente preciso, a saber, por hallarse 'naturalmente' inmerso en 'situaciones que forzosamente ha de resolver por decisión, con la vista puesta en diversas posibilidades. Ciertamente también otras realidades, por ejemplo los animales, están en situaciones y por tanto están también en cierto sentido lato 'sujetos-a'... enfermedades, etc. Pero en el caso del hombre la situación es tal que tiene que resolverla por decisión. Por esto es por lo que excede el área de sus sustancias, y por lo que decimos que es 'sujeto-a' por excelencia. Solamente es 'sujeto-de' una vez que se ha apropiado sus posibilidades; por ejemplo sólo es sujeto de virtud o de ciencia cuando se ha hecho científico o virtuoso. En este aspecto, la sustantividad no sólo es distinta de la subjetualidad, sino que es fundamento de ésta; la sustantividad es el fundamento de ser 'sujeto-a', y ser 'sujeto-a' es el fundamento de ser 'sujeto-de'. Los griegos no hablaron más que de propiedades, distinguiéndolas sólo por su contenido, pero no observaron que antes que por su contenido, las propiedades se distinguen por el modo mismo de ser propias: unas lo son por 'naturaleza', otras por 'apropiación'. Lo primero se da en las sustantividades meramente sustanciales, lo segundo en las sustantividades superiores." (Zubiri, 1986, pp. 343-345) Es decir, en el ser humano. El ser humano es esa realidad que tiene propiedades por apropiación. Y esas propiedades, en la medida en que empiezan por no ser propias, son posibilidades. Por eso lo moral es físicamente "apropiación" y esta apropiación se inscribe en el orbe de las "posibilidades".

Sin embargo, de un tiempo a esta parte el término sobre el que gira la ética en general no es el de "posibilidad", que ya nunca lo fue, sino el de "valor". Se vuelve a hablar, por eso, de ética de los valores. Historia curiosa ésta, la de la ética de los valores. La ética de los valores nace con Max Scheler, que publicó en el año 1913 en el Anuario editado por Husserl la primera parte de su conocida Ética (así fue traducida al español en 1948) (Scheler, 2001), y tres años más tarde la segunda parte. Esta ética del valor hizo fortuna en la filosofía continental en los años 20 y 30. En Alemania, por ejemplo, influyó en Nicolai Hartmann, que publicó en 1926 su Ética, y en España se hizo eco de la teoría del valor Ortega y Gasset con la publicación, en 1923, de "Introducción a una estimativa. ¿Qué son los valores?" (Ortega y Gasset, 2005). Sin embargo, después de la Segunda Guerra Mundial la ética de los valores comenzó a declinar, casi hasta nuestros días. Hace algunos años, decía un profesor mío al respecto: "Durante los últimos decenios se le ha venido prestando poca atención en los ambientes académicos; si ello habla en contra de la teoría o más bien en contra de esos ambientes, es cuestión que preferimos dejar abierta." (Rodríguez Duplá, 2001).

La verdad es que, al menos en el campo de la bioética, en concreto de la bioética norteamericana, en estos últimos años ha comenzado una recuperación paulatina de la noción de valor. Pero ha sido una recuperación también muy curiosa. La ética del valor había influido ya en sus primeros años de furor en diversos campos, especialmente en estética, derecho y pedagogía. Este último campo, como se sabe, ha sido muy desarrollado por varios filósofos pragmatistas norteamericanos, entre ellos, J. Dewey. Dewey maneja la noción de valor y de valoración, pero no en el mismo sentido que Scheler. Esto le llevó a polemizar con los del otro bando, los positivistas y emotivistas, avivando el debate sobre la dicotomía hechos y valores, sobre si los valores son o no subjetivos, etc. (Dewey, 2008). Aunque la idea de Dewey es que los valores no son subjetivos, la tesis que acabó imponiéndose en pedagogía, por influencia del método científico como clave para la educación y por la hegemonía positivista del mundo académico norteamericano tras la Segunda Guerra Mundial, es que sí lo son y por tanto, respecto de ellos, había que mantenerse "neutral". Esta neutralidad ha sido muy combatida últimamente, por ejemplo, por Amy Gutmann (Gutmann, 2001), y otros, y ello ha influido positivamente en la paulatina introducción de los valores en bioética, aunque no es tarea acabada.

\section{EL VALOR COMO CANON DEL ESBOZO DE POSIBI- LIDADES}

Pero volvamos a Zubiri. También en España se ha acabado introduciendo la noción de valor en bioética, aunque tras un largo peregrinaje por otras nociones. Una de las razones fue la siguiente. El tema del valor había quedado como una cuestión menor en toda la obra madura de Zubiri, probablemente debido a la lectura de algunos textos fuera de su contexto. Sin las debidas claves hermenéuticas, se generaron falsas interpretaciones sobre el tema del valor. Como ejemplo, he aquí un texto de Zubiri que puede llevar a una interpretación errónea de la importancia del valor en su 
obra: "Esta historia de los valores ha sido la tortura de la filosofía desde hace setenta años. Ni el bien es un valor, ni la verdad es un valor, ni la belleza es un valor; son modos de actualidad de las cosas; la manera como las cosas por su propia realidad quedan, precisamente, en la inteligencia, en la voluntad y en el sentimiento del hombre." (Zubiri, 1992, p. 357). Como comenta D. Gracia, "la lectura apresurada de este párrafo ha llevado con frecuencia a pensar que Zubiri reniega de la teoría el valor. Y no es verdad. Lo que dice es que los trascendentales verum, pulchrum y bonum no son valores. Lo cual es sobradamente obvio. Con la teoría de los valores, Zubiri hace lo mismo que con toda la fenomenología. La critica muy duramente, pero no porque no la acepte, sino porque considera que no ha sido suficientemente radical, al no descubrir la aprehensión primordial de realidad. Todo el problema del sentido, propio de la fenomenología, se mueve, para Zubiri, en el plano del logos. El hecho de que critique su falta de radicalidad, no quiere decir que niegue sus contribuciones al nivel del logos. Este ha sido, repito, un error muy frecuente de interpretación de su pensamiento." (Gracia, 2009a, p. 138).

Es a partir de los años 90 cuando comienza una nueva lectura del tema del valor en Zubiri, primero, con la publicación por parte de A. Pintor Ramos de una obra dedicada a cuestiones que tiene que ver con el "sentido", Realidad y sentido (Pintor Ramos, 1993, p. 113), y más tarde con la publicación de algunos artículos de D. Gracia (2005 y 2009a). Fundamental para esta reconstrucción de la cuestión del valor son dos cursos orales de Zubiri: "El problema del mal", de 1964, y "Reflexiones filosóficas sobre el sentimiento estético", de 1975 (Zubiri, 1992). La tesis defendida ahora es que el valor se asemeja a las simples aprehensiones que Zubiri describe en Inteligencia y Logos. He aquí cómo lo explica D. Gracia: "En el orden de la inteligencia sentiente, el logos inicia su andadura a través de lo que Zubiri llama 'aprehensión dual', es decir, la aprehensión de una cosa entre otras, en el campo de realidad. Esto comienza por lo que Zubiri llama 'simple aprehensión' en la línea de la inteligencia sentiente, que para él no es aprehensión primordial, ni por tanto da verdad real. La simple aprehensión está ya mediada por múltiples elementos culturales, educativos, etc. La simple aprehensión es construcción, construcción libre el sujeto. Pues bien, cabe preguntarse si hay algo parejo a la simple aprehensión en el orden del sentimiento. $Y$ la respuesta es que sí, y que eso es lo que en el curso de 1964 Zubiri llama 'estimación'. Este término llega a Zubiri a través de Husserl, de Scheler y de Ortega. Una cosa es sentir y otra muy distinta es estimar. El estimar no es parte de la aprehensión primordial de realidad. Por tanto, la estimación de Zubiri no tiene mucho que ve con lo que por ella entiende Scheler, una especie de intuición de esas esencias ideales que llama valores. La estimación nos permite, eso sí, identificar los contenidos dados en el sentimiento, diferenciar unos de otros, e incluso nombrarlos y valorarlos. Lo que es el concepto en el orden de la inteligencia sentiente, es el valor en el del sentimiento afectante. Esto lo vio ya $\mathrm{n}$ toda claridad Antonio Pintor-Ramos, cuando en 1993, en su libro Realidad y sentido, escribe: 'Eso que Zubiri, siguiendo una tradición que viene de Brentano, llama 'estimación' me parece paralelo al [lugar] que dentro de lo intelectivo ocupan las 'simples aprehensiones'." (Gracia, 2009a, pp. 146-147).

Por tanto, con la introducción de la estimación del valor a nivel del logos, al lado de las simples aprehensiones, hemos enriquecido la descripción de los contenidos de realidad aprehendida. No sólo juzgamos intelectualmente de las cosas, sino que también las estimamos y hacemos juicios de valor sobre ellas. El valor pasa a ser un ingrediente más del análisis que sobre la realidad lleva a cabo el logos desde el punto de vista del sentimiento. Igual que existe una noema de carácter intelectivo, que suele llamarse genéricamente idea o concepto, existe también un noema de carácter emocional. Este noema es ahora llamado valor. En Zubiri no es exactamente un noema, pero valga el término para entendernos. Lo importante es expresar el lugar y el sentido que posee el valor en su filosofía. Y esto es lo que dice D. Gracia: "mi tesis es que el nombre propio de estos noemas son los valores, como dijo Husserl, desarrolló Scheler y, a mi modo de ver, acepta Zubiri." (Gracia, 2009a, p. 149).

Pero el logos no es más que un momento estructural de la intelección. Más allá de él hay otro momento, que Zubiri llama razón. La razón marcha allende lo aprehendido en el campo, en busca de su fundamento. Ahora bien, la razón realiza esta marcha apoyada en la aprehensión primordial y en todas las intelecciones afirmativas que el logos ha aprehendido ya. Este apoyo significa que lo real aprehendido en el campo es ahora, en intelección racional, mensura o canon de la realidad profunda. Algunos ejemplos para aclarar lo que acabo de decir. "En el campo más elemental de realidad hemos aprehendido intelectivamente que las cosas materiales que en él hay son lo que Ilamamos 'cuerpos'. En la marcha allende el campo se ha marchado pensando durante muchísimas centurias que las cosas 'allende' son también cuerpos; ciertamente tal vez de otra clase, pero cuer- 
pos también. Ha hecho falta la conmoción de la física cuántica para introducir muy dificultosamente, pero con éxito indiscutible, la idea de que lo real allende, no siempre es cuerpo. Las partículas elementales, en efecto, no son corpúsculos (tampoco son ondas en sentido clásico, pero dejemos de lado este aspecto) sino que son otra clase de cosas materiales. [...] Pero no hay sólo esto. En la intelección de las cosas reales dentro del campo se había decantado en nuestra intelección no sólo la intelección de que las cosas reales son cuerpos, sino también y sobre todo la intelección de que ser real es ser 'cosa', en el sentido que tiene hoy el vocablo cuando se habla, por ejemplo, de 'cosismo'. Este era el metro de realidad: la marcha allende el campo se llevaba a cabo pensando que la realidad como mensurante es 'cosa'. Hizo falta una intelección mucho más difícil que la de la física cuántica para inteligir que lo real puede ser real y sin embargo no ser cosa. Ser, por ejemplo, persona. Entonces no sólo se amplió el campo de cosas reales, sino que se han ampliado eso que pudiéramos llamar los modos de realidad. Ser cosa es tan sólo uno de esos modos; ser persona es otro." (Zubiri, 1983, pp. 55-56).

Pues bien, esto que vale para el conocimiento metafísico o científico, vale también para el conocimiento de los valores y para el conocimiento moral. Como dice Zubiri, la marcha de la razón no es puramente teorética: "pensar ciertamente no es sólo pensar lo que las cosas son desde un punto de vista por así decirlo teorético. No se piensa sólo en la realidad propia de lo que llamamos cosas, sino que se piensa también por ejemplo en lo que hay que hacer, en lo que se va a decir, etc." (Zubiri, 1983, p. 30). Por tanto, con el enriquecimiento del campo por vía estimativa, ahora tenemos un nuevo canon para medir la realidad profunda de las cosas. Ahora podría medir la realidad profunda, por ejemplo, en términos de "valor", y decir que lo que tengo que hacer en mi vida es "realizar valores". Con lo cual, ya entramos en la dimensión práctica de la intelección humana, en eso que se ha llamado desde antiguo "razón práctica", y que tiene que ver con la ética y la bioética.

Decíamos al principio que el concepto central en torno al cual gira el hecho moral en el curso de 1953/4 era el de "posibilidad". Este concepto vuelve a aparecer en otros textos de Zubiri, por ejemplo, en el análisis de la historia como entrega de posibilidades (Zubiri, 2006), etc. Y, finalmente, en la trilogía, el concepto de posibilidad es un momento fundamental de la intelección racional (Zubiri, 1983, pp. 135-158). Lo que la razón hace es esbozar posibilidades de lo que esto o lo otro puede ser. Esbozar es un modo de pensar. Y como dice Zubiri, "se piensa siempre y sólo en posibilidades. Si pienso en el paseo que voy a dar, o en el viaje que voy a emprender, o en lo que es en realidad eso que llamamos luz, en lo que pienso formalmente es en el paseo que puedo dar, o en el viaje que puedo emprender, o en las posibilidades reales para que se produzca eso que Ilamamos luz. El objeto formal de la actividad intelectiva es lo que lo real podría realmente ser." (Zubiri, 1983, p. 142). Ahora bien, cuando se trata de pensar en lo práctico, en lo volitivo u operativo, el concepto de posibilidad cobra todavía más sentido. Según decía Zubiri ya en el curso "Sobre el problema del mal", "el objeto propio y formal de una volición es la posibilidad real. [...] El término formal es la realidad, pero la realidad en tanto que condición fundante de posibilidades. Y lo que el hombre formalmente elige son las posibilidades reales, las que la cosa realmente ofrece, sea porque el hombre se las encuentre, sea porque el hombre forje sobre las posibilidades de la cosa las posibilidades que ella le puede ofrecer. En eso consiste la volición por razón de su objeto (Zubiri, 1992, p. 268).

Por tanto, la posibilidad es la clave de bóveda, no sólo de la intelección racional, sino de la intelección racional práctica, esto es, de la realización humana. Antes de realizar algo, o para realizarlo, lo primero que el ser humano tiene que hacer es esbozarlo, proyectarlo como posibilidad. El problema, el primer problema, quizá, es que a todo ser humano se le presentan un número indeterminado de posibilidades de realización o apropiación entre las que ha de elegir. $Y$ tras este problema, el segundo problema, seguro, es que no puede delegar la decisión en otro. Ciertamente, "las posibilidades que cada uno tiene, o bien emergen de uno mismo o de los demás" (Zubiri, 1986, p. 311), o dicho de otro modo, o bien son creadas por uno mismo (libre creación individual), o bien son entregadas por otros a lo largo del tiempo (depósito social e histórico). Pero esto no evita el acto personalísimo de elección o apropiación, pues en ello le va a uno su vida moral. Por eso, un tercer problema, el más grave ahora, es el de saber discernir qué posibilidad es la mejor, la que le realiza a uno mejor. Aquí es donde pensamos que está tomando un papel decisivo la noción de valor. El valor es en bioética el canon de evaluación de los conflictos morales, que no son sino conflictos de posibilidades. Lo que nos apropiamos son posibilidades, pero esas posibilidades, en la medida en que se nos presentan como múltiples, distintas y contrapuestas, es preciso someterlas a un proceso de 
evaluación. Es justo la irrupción del "valor". Las posibilidades objeto de realización son ahora buenas o malas, mejores o peores, en función de lo que valen. De ahí que se diga que la ética es la "realización de valores", como, por otra parte, se venía diciendo ya dentro de la ética de los valores.

Ahora bien, la expresión "realización de valores" puede ser equívoca desde el punto de vista zubiriano. En primer lugar, lo que hacemos propiamente no es realizar valores sino apropiarnos posibilidades. Esto significa, por un lado, que la apropiación recae sobre la realidad y consiste básicamente en la aceptación de una posibilidad real. Por otro lado, significa que el valor no es más que el canon o medida de esas posibilidades que se presentan en una situación determinada como viables. Según dice Zubiri, "ciertamente, puedo ir del valor al bien. Pero entonces el valor es mera ratio cognoscendi del bien; en manera alguna es ratio essendi" (Zubiri, 1992, p. 223). Es preciso insistir en ello: el modo de discernir las posibilidades buenas de las malas, o las mejores de las peores, es conociendo, analizando qué valores poseen. El valor es la medida de esas posibilidades, su sistema de referencia, pero no la posibilidad en cuanto tal.

En segundo lugar, , "realizar" no es dar realidad a algo que no la tiene, dado que los valores, igual que los fictos y las ideas, son físicamente reales (reales en sentido zubiriano). Como dice Zubiri, "lo irreal mantiene el físico carácter de realidad -e insisto en la palabra físico-, en el cual se inscriben las ficciones o las ideas. No es que junto a la realidad que realmente existe haya un mundo de ficción, sino que el carácter físico de realidad aloja por un lado las cosas reales que veo y además las ficciones o las ideas que yo forjo dentro de ese campo" (Zubiri, 2005, p. 137). En términos zubirianos, "realizar" un valor no es pues darle realidad, sino apropiarme la posibilidad que valoramos como buena, justa, etc., es decir, aceptarla, y en este sentido, hacerme con su poder. En definitiva, no se trata de que el ser humano realice valores, sino que son los valores, o las posibilidades buenas, justas, etc., realizan al ser humano.

En tercer lugar, lo que cabría añadir por último es que el valor no es, quizá, el único canon o modo de medir la proyección y realización de posibilidades. No hay ecuación perfecta entre "apropiación de posibilidades" y "realización de valores". De hecho, en el Zubiri de los años 50, el valor no era más que un modo de evaluar una dimensión de las posibilidades apropiables, pero no el único ni el más importante. Hoy, en el terreno de la bioética, sí parece ser el más importante, y quizá por ello corremos el riesgo de considerarlo como el único.

Evidentemente, hecha esta precisión, nada impide ahora seguir utilizando la expresión "realización de valores" como equivalente a "apropiación de posibilidades".

\section{LA IDEALIZACIÓN Y POSITIVACIÓN COMO FASES DE LA APROPIACIÓN DE POSIBILIDADES (O LA REALI- ZACIÓN DE VALORES)}

Como hemos visto, la inteligencia humana tiene una estructura que permite analizar la aprehensión de las cosas a distinto nivel (Zubiri, 1991, pp. 9-15). Se puede aprehender lo real en y por sí mismo, pero ocurre que casi siempre nos encontramos aprehendiendo lo real entre otras cosas, o en función de otras cosas, o distanciadamente. Esta aprehensión dual puede ser también muy distinta. Se puede aprehender lo real moviéndonos en el ámbito o campo de realidad aprehendida, o se puede marchar allende esta aprehensión, en busca de su fundamento. A lo primero, como ya vimos, llama Zubiri logos, mientras que a lo segundo llama razón. Tanto el logos como la razón construyen la realidad dada primordialmente, pero de modo muy distinto. El logos construye la realidad "ideando"; en cambio, la razón construye la realidad "idealizando". Aunque zubiri no utiliza explícitamente esta terminología, a continuación voy a servirme de ella para completar el análisis de la construcción de la bioética.

Pues bien, la construcción de ideas y valores en el campo es lo propio del logos, mientras que el esbozo de posibilidades y la realización de valores es lo propio de la razón. Por tanto, tanto las ideas como las posibilidades son construidas, pero de modo muy distinto. Las ideas y valores son construidas por el logos, mientras que las posibilidades son más o menos pensadas. Para lo primero basta con un acto de "ideación"; en cambio, para lo segundo, ese acto es de "idealización". Fundamental la diferencia. La ideación ya la describió Zubiri en los tres tomos de Inteligencia sentiente. La idealización en parte sí y en parte no, porque no está adscrita a una única facultad. En parte sí, porque es lo que hace la razón, y en parte no, porque es lo que, complementariamente, pertenece también al sentimiento afectante y a la voluntad tendente. La ideación tiene que ver con el logos en su amplio espectro (percepción, ficción, concepción, estimación, afirmación, valoración, etc.), mientras que lo idealización tiene que ver con la razón, con la intelección racional (postular, modelar, confrontar, proyectar, etc.), apoyada esta intelección en los contenidos del campo dados por vía intelectiva, emocional y volitiva. 
Idear es formar ideas. La inteligencia, al aprehender las cosas, idea, forma ideas de ellas. La ideación es el acto más común de la inteligencia. Idealizar es otra cosa. No es formar ideas a partir de la realidad, puesto que éstas ya están formadas en la aprehensión campal, sino proyectarlas más allá de esa aprehensión. La ideación es todavía un acto que nos retiene en la aprehensión. La idealización va más allá de la aprehensión, allende ella. Es la diferencia entre el "sería" y el "podría ser" en términos zubirianos. El DRAE dice que "idealizar" es elevar las cosas sobre la realidad sensible por medio de la inteligencia o la fantasía. Esto en Zubiri es imposible, no hay una realidad sensible y otra inteligible, sino que todo es realidad. Lo que sí es posible es ir de la realidad aprehendida a una realidad allende la aprehensión. $Y$ esto es lo que aquí vamos a entender por "idealizar". De hecho, "ideal", también según el DRAE, es sinónimo de "prototipo", "modelo" o "ejemplar" de perfección. Entonces, la pregunta es la siguiente: cuando valoramos lo que hay que hacer, ¿estamos ideando o idealizando? Se habla de una "comunidad ideal", o de "belleza ideal" o de "excelencia moral", que viene a ser lo mismo, pero respecto de la bondad. ¿Qué son estas valoraciones, ideaciones o idealizaciones? Una teoría científica es una posibilidad ideal, y lo es también la belleza de un cuadro o la opción óptima ante un conflicto moral. Todo esto son posibilidades, pero son posibilidades pensadas, estimadas o queridas, cada una en su caso, es decir, idealizadas con el canon "valor".

Pero tratándose de la concepción zubiriana de la razón, la idealización no es más que una fase, la primera, en el proceso de apropiación o realización de posibilidades. Toda apropiación posee dos fases 0 dos momentos, una de idealización y otra de positivación. La idealización corresponde a lo que Zubiri llama "esbozo de posibilidades", mientras que la positivación se asemeja a la experiencia o "verificación". La verificación consiste en traer al campo lo esbozado. El esbozo posee la característica de la universalización, mientras que la verificación particulariza el esbozo. La universalización consiste en pasar de lo que "yo quiero ser" - puesto que las posibilidades "se constituyen en orden a lo que yo quiero ser" (Zubiri, 1992, p. 267)- a lo que todo "podría ser". No toda idealización implica universalización, pero "una moral que no pase la prueba de la universalidad, dice Zubiri, está minada radicalmente por su base" (Zubiri, 1986, p. 431). La particularización consiste en pasar de lo que "podría ser" a lo que "puede ser".
Todo esto que aquí hemos descrito con terminología básicamente zubiriana en dos pasos, el de idealización y el de positivación, ha sido la estructura básica en la que D. Gracia ha asentado últimamente su análisis de la ética y de la bioética. "La inteligencia, decíamos, proyecta lo que pretende llevar a cabo, y para ello necesita, entre otras cosas, valorar el proyecto. En tanto que proyecto, se trata de algo que aún no es real y que por consiguiente tiene carácter puramente ideal. Sólo si se realiza, lo proyectado cobrará realidad. En la valoración, pues, hay un momento ideal y otro real. Al valor realizado lo hemos llamado cultura. Pero también es cultura el momento de idealidad, que todos proyectamos necesariamente. Pongamos un ejemplo. La justicia es un valor, como lo son también la belleza, la solidaridad, la paz, la salud, la vida, etc. Mi deber es siempre realizar los valores que aún no son reales de modo completo, como la justicia. Eso significa que yo estoy proyectando o imaginando una sociedad en la que la justicia esté plenamente realizada. Los valores tienen un momento de idealidad, que consiste en la proyección ideal de un mundo y una sociedad en la que ese valor esté totalmente realizado, de tal forma que permita vivir de modo pleno a todos los seres humanos. Ese momento de idealidad es absolutamente necesario en el proyecto humano. De ahí que buena parte de las producciones culturales tengan por objeto diseñarlo, dotarlo de contenido. Los mitos, las religiones, las filosofías, el folclore, la novela, la poesía, están continuamente diseñando ese mundo ideal en el que los principales valores cobren realidad plenaria. El reino de Dios de la tradición cristiana se caracteriza porque en él se dan en plenitud ciertos valores como la verdad, la justicia, el amor y la paz. Y con variantes no sustantivas, lo mismo sucede en el paraíso musulmán, o, bajo forma secularizada, en el reino de los fines de Kant o en el paraíso del proletariado marxista. Los valores no están plenamente realizados, y la obligación moral de todo ser humano no es otra que hacer lo posible para que cobren realidad cuanto antes y de modo pleno." (Gracia, 2009b, p. 700).

El proceso de apropiación o realización según estas dos fases es lo que puede llamarse ejercicio de responsabilidad, en el sentido de respuesta a la realidad que nos lanza y posibilita que nos determinemos en ella. La responsabilidad es la doble tarea de esbozar posibilidades y apropiarlas en orden a su previsible verificación (en este caso, en orden a la configuración o realización humana), por tanto, quedando en disposición de ratificar o rectificar la decisión. 


\section{LA APROPIACIÓN DE POSIBILIDADES EN BIOÉTICA}

El término "bioética" apareció por primera vez en lengua alemana, acuñado por el teólogo protestante Fritz Jahr el año 1927. Jahr la definió como la ética de las relaciones de los seres humanos con los animales y las plantas. Esto significaba dar un duro golpe a la ética paradigmatica del momento: la ética kantiana. Para Kant el ser humano es el centro del universo y, por tanto, los deberes se determinan con el criterio de universalización según ordena el imperativo categórico. Lo que ahora dice Jahr es justo lo contrario: que todos los seres vivos tienen que ser tenidos en cuenta en la determinación de los deberes morales y, por tanto, que hay que elevar el criterio de universalización a criterio de globalización. La consecuencia última de esta idea es que el imperativo categórico se transforma en un imperativo de responsabilidad, llamado por Jahr "imperativo bioético".

Sin embargo, esto que surgió en Alemania, no tuvo ninguna influencia. Fue algo que nació pero no maduró. Se echó a perder y desapareció completamente. Fue ahora últimamente cuando se descubrió el desconocido origen germano del término bioética. La bioética que hoy conocemos y practicamos en mucha medida es la que vuelve a surgir en EEUU hacia el último tercio del siglo XX. Fue R. Van Potter quien, ahora en lengua inglesa, crea de nuevo el término bioética. En este hecho influyen varios factores, unos biológicos, otros ecológicos y, finalmente, otros biomédicos. Tales son el desarrollo espectacular del conocimiento biológico del ser humano, la toma de conciencia de los riesgos de la investigación científica, los nuevos avances tecnológicos aplicados a la biomedicina y la emancipación de los pacientes. De importancia capital fue, además, la formación de Comités de ética en algunas fundaciones e instituciones hospitalarias.

Ahora bien, el caso de España, muy receptiva a la bioética norteamericana, presenta algún factor distinto. Aquí no nace propiamente la bioética, pero sin embargo sí entró y maduró muy pronto. Lo que hay que decir, entonces, es que aquí había un suelo propicio para ella, justo lo contrario de lo que sucedió en Alemania. Este suelo lo constituyen ciertas instituciones democráticas, cierto sistema sanitario público, ciertos profesionales excelentemente formados y, sobre todo, cierta filosofía que permitía "repensar la bioética en España". Todos estos factores llevan a afirmar que la bioética en España es hoy muy distinta de la bioética norteamericana. Aquí no nos expresamos principalmente en términos de derechos y deberes, como en el mundo germano, ni de principios y consecuencias, como en el mundo anglosajón, pero hemos sabido sustituir el lenguaje clásico de las virtudes por el lenguaje más moderno de los valores, y lo hemos hecho muy rápidamente, quizá como pocos países de nuestro entorno. Pero el recorrido no ha sido fácil.

En cuanto a la primera fase, la idealización, en la bioética española ha ocurrido lo mismo que en ética en general. Se ha comenzado idealizando, y luego se ha querido escapar de la idealización, saltando a la positivación, sobre todo a la positivación jurídica. Este salto se ha dado en el vacío, porque no podemos dejar de idealizar. De hecho, en la bioética española de lo que hemos pasado ha sido del "idealismo de los principios" al "idealismo de los valores". Porque la cuestión es la siguiente: ¿qué valores tenemos que realizar? Los que aún no están realizados, por tanto, los que hemos idealizado y estimado como posibilidades perfectas. Y como lo "perfecto" es "la plenitud ideal de algo" (Zubiri, 1992, p. 247), los valores que al final guían nuestras decisiones son idealizaciones racionales. Esto tanto en lo que se refiere a los llamados "valores intrínsecos" como a los llamados "valores instrumentales". Terminología ésta ajena a la filosofía de Zubiri, pero, recuperable, si es el caso, a nivel del logos y de la razón. Aunque yo preferiría hablar de "valores finales" y "valores instrumentales".

En cuanto a la segunda fase, la positivación, también aquí se han cometido algunos errores en la bioética española, porque no existe un único modo de verificar los esbozos de posibilidades. Por más que se intente, no sirven criterios cuantitativos, o dicho en términos filosóficos, absolutos o absolutistas. Existe una gran pluralidad de criterios no cuantitativos que tienen que ver con circunstancias no sólo personales, sino económicas, sociales, culturales, políticas y científicas de una comunidad, nación o civilización. ¿Cómo verificar entonces los esbozos, cómo pasar de lo universal a lo particular, de lo esbozado idealmente a lo positivamente verificado? Aquí hay que echar mano de eso que desde Aristóteles se viene llamando sabiduría práctica o "prudencia", que no es más que la puesta en marcha de la razón práctica en su función deliberativa. La deliberación es el modo de experiencia de la razón práctica. No es un mero método de toma de decisiones, como suele decirse, sino el modo de experiencia prudencial. Así entendida, la deliberación permite adaptar el esbozo de posibilidades a una situación concreta. Esta adaptación es aquí la antesala de la opción, es decir, de lo que tiene como término la ad-opción de una posibilidad en vez de otra. 


\section{CONCLUSIÓN}

La bioética es hoy una de las de las tres o cuatro grandes revoluciones que se han producido en los últimos siglos en el campo científico-filosófico, hasta el punto de constituir todo un paradigma moral, dicho en términos kuhnianos, un modo completamente nuevo de abordar los problemas morales. De ahí que sea apropiado hablar de la bioética como la "revolución copernicana" en ética (Pose, 2009). Su nacimiento y maduración, en todo caso, no fue fácil. La bioética nació por primera vez en el mundo germano a principios del siglo $X X$. Y aunque allí no maduró, la idea de Jahr era una auténtica revolución en ética y, por lo tanto, antes o después habría de irrumpir de nuevo. Así sucedió algo más tarde, pasado casi medio siglo, en EEUU, donde nació y se consolidó de modo independiente.

El caso de España es peculiar. España es un país receptor o adoptivo de la bioética norteamericana, pero que pronto toma identidad propia. Quiere decirse que la bioética no nació en España, pero sí maduro. Hoy es uno de los países europeos que posee una bioética más desarrollada. Ello tiene que poseer alguna explicación. En España existen algunos factores comunes a otros países que hicieron posible que la bioética procedente inicialmente de EEUU se consolidara. Pero existían otros factores que la hicieron madurar de modo particularmente distinto. Esos factores tienen que ver con su cultura intelectual. La entrada a princi- pios del siglo XX de la filosofía germana en España fue decisiva en la constitución de un suelo propicio para el desarrollo, primero, de la filosofía española, y más tarde, para la bioética. Todo el tema de la reconstrucción de la bioética desde la idea de valor en el contexto de la filosofía de Zubiri intenta expresar esta idea.

Por eso, aunque la científica fue, inicialmente, una de las circunstancias que provocó el nacimiento de la bioética, hoy podemos afirmar que no es la circunstancia que produjo su consolidación en España. Evidentemente, este hecho sigue sin llegar a todos. De ahí que la bioética para muchos siga siendo una ética de la ciencia, o una ética positivista, un apéndice de la ciencia o del sistema jurídico. Es mucho más que eso, y sobre todo, es algo muy distinto de eso: es la ética que intenta gestionar los valores humanos más allá de los hechos científicos.

Una última cuestión: ¿Todo esto que hemos descrito es Zubiri? En realidad, Zubiri no se ocupó en su etapa madura de la razón práctica, pero sí del proceso de idealización y verificación. Por eso, aunque en su filosofía última no aparecen expresiones como "responsabilidad", "prudencia" o "deliberación", todo parece indicar que la estructura noológica de la intelección permite dar el paso hacia lo volitivo y lo moral en la línea que hemos apuntado. Aunque, en honor a la verdad, este paso lleva años dándolo, para muchos, el maestro de la bioética en España, y creo que en Hispanoamérica: Diego Gracia (2004 y 2007a).

\section{BIBLIOGRAFÍA}

Dewey, J. (2008). Teoría de la valoración. Madrid: Biblioteca Nueva.

Gracia, D. (2004). Como arqueros al blanco. Madrid: Triacastela.

Gracia, D. (2005). Los sentimientos en la vida moral: otra visión del emotivismo. En VV.AA.: La bioética, mosaico de valores. Madrid: Asociación de Bioética Fundamental y Clínica, pp. 33-66.

Gracia, D. (2007a). Fundamentos de Bioética. Madrid: Triacastela.

Gracia, D. (2007b). Procedimientos de decisión en ética clínica. Madrid: Triacastela.

Gracia, D. (2009a). Zubiri en los retos actuales de la Antropología. En Pintor Ramos, A. (coord.) Zubiri desde el siglo XXI. Salamanca: Publicaciones Universidad Pontificia de Salamanca, pp.111-158.

Gracia, D. (2009b) La ética de la objeción de conciencia. Anales de la Real Academia de Medicina, 126, 4, pp. 691-712.
Gutmann, A. (2001). La educación democrática. Una teoría política de la educación. Barcelona: Paidós.

Ortega y Gasset, J. (2005). Obras Completas (tomo III: 1917-1925). Madrid: Taurus.

Pintor Ramos, A. (1993). Realidad y sentido. Desde una inspiración zubiriana. Salamanca: Publicaciones Universidad Pontificia de Salamanca.

Pose, C. (2009). Lo bueno y lo mejor. Madrid: Triacastela.

Rodríguez Duplá, L. (2001). Ética, Madrid: BAC.

Scheler, M. (2001). Ética. Madrid: Caparrós Editores.

Zubiri, X. (1983). Inteligencia y razón. Madrid: Alianza/Sociedad de Estudios y Publicaciones.

Zubiri, X. (1994). El hombre y Dios. Madrid: Alianza/Fundación Xavier Zubiri.
Zubiri, X. (1986). Sobre el hombre. Madrid: Alianza.

Zubiri, X. (1991). Inteligencia sentiente. Inteligencia y realidad. Madrid: Alianza/ Fundación Xavier Zubiri.

Zubiri, X. (1992). Sobre el sentimiento y la volición. Madrid: Alianza Editorial/Fundación Xavier Zubiri.

Zubiri, X. (2005). El hombre: lo real y lo irreal. Madrid: Alianza/Fundación Xavier Zubiri.

Zubiri, X. (2006). Tres dimensiones del ser humano: individual, social, histórica. Madrid: Alianza/Fundación Xavier Zubiri. 